\title{
A Comparative Study of Actual and Perceived Academic Competence of Iranian EAP Postgraduate Students
}

\section{Reza Khani ${ }^{1} \&$ Maha Ariyanmanesh ${ }^{1 *}$}

\footnotetext{
* Correspondence:

m.arianmanesh@yahoo.com

1. Department of English Language and

Literature, Ilam University, Iran
}

Received: 23 November 2018

Revision: 16 January 2019

Accepted: 7 February 2019

Published online: 20 March 2019

\section{Abstract}

Academic writing is a major concern for many university students. Despite extensive literature on students' academic writing, little attention has been focused on students' writing experience and practice in higher education. To fill this gap, the present study compared actual and perceived academic writing competence of postgraduate students who were enrolled in English for Academic Purposes (EAP) courses. First, measures of actual and perceived academic writing competence were developed and validated in Phase 1 , using a separate sample of EAP postgraduate students $(n=391)$ in Ilam province, Iran. Phase 2 examined postgraduate students' academic writing competence perceptions and the ways through which their perceptions might have differed from their actual academic performance. Then the developed measures of actual and perceived academic writing competence, which exhibited acceptable reliability and good model-data fit, were distributed among a sample of 210 EAP postgraduate students from nine different academic fields. The results of data analysis revealed significant differences in perceptions and actual academic practices of students across different academic fields of study.

Keywords: academic writing, actual competence, EAP postgraduates, perceived competence, research articles 


\section{Introduction}

Academic writing is a productive activity that demands critical reading of educational materials and reconstructing these materials based on one's own interpretations and understandings (Badley, 2009). No doubt, it is an important and difficult undertaking, especially, for many graduate students, who after spending years studying and searching a particular research topic, desire to publish their manuscripts (Wilkinson, 2015). The constructive and creative nature of academic writing may be a source of difficulty; in that, it demands a critical reading of educational materials (Badley, 2009). Moreover, the fact that writing is often considered a tacit knowledge can also constitute another source of difficulty. Writing is often considered a skill that is mostly acquired by students; and there seems to be neither direct instructions nor enough support from supervisors in helping students develop their writing skills. Consequently, the success at this skill is often left to chance (Jalongo, 2013).

Today, English has become the primary language of the scientific community, and the number of research articles (RAs) published in English has increased dramatically. Furthermore, the study of academic writing competence has become important from many perspectives, especially, in higher education. A great body of research exists on reasons motivating students to write academically, the language-related challenges, and the perceived difficulty associated with writing academically. However, no study so far has compared students' perceptions regarding their academic writing competence and their actual writing performance. Examining students' perceptions and actual academic writing performance is a critical topic. It will help provide the means to address a variety of issues impacting students' learning and the development of writing instruction at different levels of education. Moreover, students and teachers will be provided with information that can be helpful in identifying areas of strength and weakness. Comparing how students evaluate their writing abilities and how they demonstrate their writing abilities will tap into aspects of academic writing that may be challenging and in need of attention for students. Students can become more aware of their weaknesses and strengths in academic writing and focus on improving their weaknesses. The information can also be helpful in developing new and alternative writing activities and writing programs. Students' responses can be an indication of the extent to which the expected objectives of the educational programs are attained.

\subsection{Statement of the Problem}

Evidence has shown that academic writing poses a major difficulty for many university students. The review of literature on students' academic writing ability revealed that a great body of research has mostly been focused on the perceived difficulty associated with writing different sections of a research paper (Bardi, 2015; Hanauer \& Englander, 2011; Lee \& Tajino 2008; Maher et al., 2014; Martin et al., 2014; Moreno, 2012; Perez-Llantada et al., 2011). The findings have shown that students face writing-related challenges, which prevent them from writing and submitting their manuscripts to English-medium international journals. These challenges lie in linguistic and nonlinguistic resources they need in writing academically. Some students reported being unfamiliar with the academic writing conventions that dictate the way different sections of a research article should be written (i.e. the introduction, methods, results, and discussions sections) (Gea-Valor et al., 2014; Martin et al., 2014). Regarding students' actual writing practices, Alavi and Tahririan (1996), Atai (2000), and Tahririan (1987) found that students lacked languagerelated knowledge of writing. EAP/ESP students' level of general English proficiency was low. Furthermore, Iranian EAP/ESP students lacked sufficient writing skills (Mazdayasna \& Tahrririan, 2008). In the context of Iran, students faced a truncated English language curriculum that leads to underdeveloped writing skills (Naghdipour, 2016).

However, no research study has been conducted on comparing students' perceptions of their academic writing competence and their actual writing performance. To fulfill this gap in research on academic writing, in the present study, perceptions of students regarding their academic writing skills and their actual performance in academic writing is investigated. Particularly, this study aimed to compare actual and perceived academic competence of postgraduate students from different academic fields. Academic competence was defined as students' abilities and skills in writing academic research articles. Their actual academic competence illustrated their proficiency in writing research articles (RAs) as they employed different structural, organizational, and rhetorical features. Students' perceived academic competence, on the other hand, would illuminate their perceptions and attitudes of their knowledge of different components of academic writing. The study was conducted in two phases. Since we could not find any valid and reliable measures of actual and perceived academic writing competence, we had to develop and validate such measures. Therefore, in the first phase of the study, instruments that assess postgraduates' perceived and actual academic competence in writing research articles in nine disciplines (e.g. Agriculture, Mathematics, Architectural Engineering, Chemistry, Chemical Engineering, Physics, Sociology, Economy, and Applied Linguistics) were 
developed and validated. In the second phase of the study, students' perceptions of their academic writing competence were compared with their actual academic performance in order to explore whether there was a significant difference. This study addressed the following research questions:

1. What is EAP students' actual academic writing performance?

2. Are there any statistically significant differences between students' actual and perceived academic writing competence across different academic fields?

\section{Review of the Literature}

In the past decades, researchers examined academic writing ability of EFL/ESL students at different educational levels. Extensive discussions have been centered on the influential role of English language in academic research (BoconegraValle, 2014; Gea-Valor, Rey-Rocha, \& Moreno, 2014; Martin, Rey-Rocha, Burgess, \& Moreno, 2014; Perez-Llantada, Plo, \& Ferguson, 2011). A number of research studies have examined linguistic and non-linguistic challenges confronted by many English as a second/foreign language (ESL/EFL) students (Carrio-Pastor \& Mestre-Mestre, 2014; Fazel, 2013; Gea-Valor et al., 2014; Martin et al., 2014). In addition, ESL/EFL students' perceptions regarding academic writing have been the research focus of some researchers (Bardi, 2015; Hanauer \& Englander, 2011; Lee \& Tajino, 2008; Maher, Feldon, Timmerman, \& Chao, 2014; Martin et al., 2014; Moreno, Rey-Rocha, Burgess, LopezNavarro, \& Sachdev, 2012; Perez-Llantada et al., 2011).

Students prefer to write and publish research articles in English because English has become the primary language of the scientific community. In a number of studies students referred to this increasing importance of English language in the globalized academic world (Bocanegra-Valle, 2014; Gea-Valor et al., 2014; Martin et al., 2014; Perez- Llantada et al., 2011). The researchers found that students were motivated to write and submit research articles in English in order to gain a wider readership. Students asserted that publishing research articles in English was a way through which they could share the results of their work with other researchers around the globe. Publishing in an international journal and sharing the results of their study with readers around the globe would provide students with the opportunity to reach a wider audience. Hence, they can progress academically and professionally because publication in English high-quality journals plays a major role in decisions related to hiring, promotion, and income increment (Belcher, 2007).

Students' attitudes, perceptions, and experiences in writing academic research articles have also been investigated (Al-Badwawi, 2011; Bardi, 2015; Hanauer \& Englander, 2011; Lee \& Tajino, 2008; Maher et al., 2013; Martin et al., 2014; Moreno et al., 2012; Perez-Llantada et al., 2011). It was found that students' writing was influenced by a number of factors. Some factors were related to students' characteristics such as English language proficiency and past writing experience. Other factors were contextual and were related to task requirements, the disciplinary and institutional contexts where students' writing took place. English proficiency was shown to be a strong determiner of students' academic writing ability. Moreno, Rey-Rocha, Burgess, Lopez-Navarro, and Sachdev (2012) found that lowproficiency students experienced more difficulty in writing in English because they faced more linguistic problems at a sentence, discourse, and even rhetorical levels than high-proficiency students did. Some EAP/ESP students revealed low levels of general English proficiency (Alavi \& Tahririan, 1996; Atai, 2000; Mazdayasna \& Tahrririan, 2008; Tahririan, 1987). Writing-related problems of more proficient students, on the other hand, were shown to be related to the register of academic discourse (Bardi, 2015).

In a sociopolitical case study, $\mathrm{Li}$ (2006) investigated the writing of nonnative doctoral students who were writing for publication in English. Writing in English was a barrier in publication for those students. The language of their manuscripts was seen as undesirable by the reviewers. In particular, students' manuscripts suffered from clarity in transferring the meaning of the sentences correctly from a pragmatic point of view. Shaw and Liu (1998) looked at learners' writing enrolled in English for Academic Purposes courses. The researchers asked students to write essays on a particular topic. The essays were administered as pre and posttest. Then students' improvement in writing was explored. Similar to Li's (2006) study, it was found that students' writing showed improvement from stylistic points rather than language proficiency. Their writing suffered from linguistic aspects, in particular, lexis, and syntax. They wrote linguistically poor sentences that were inappropriate and inaccurate.

Similarly, nearly all students, in Zhang's (2011) study faced difficulties in technical writing. The areas of difficulties were more concerned with surface level features of language. For them, appropriate use of vocabulary and expressions, sentence structures and paragraph organization, and grammar were linguistic challenges that they confronted in 
writing in English. The same results were found in Evans and Green's (2007) study. In line with Li (2006), Shaw and Liu (1998), and Zhang's (2011), grammar, lexis, and stylistic aspects of writing were the sources of difficulty. Many students adhered their weaknesses in writing to the lack of linguistic resources (i.e. lexis, syntax) (Hinkel, 2003) and to the unfamiliarity with the typical rhetorical organization and writing conventions, which dictated how different sections of a research article (i.e. the introduction, methods, results, and discussions sections) should be written (GeaValor et al., 2014; Martin et al., 2014). For example, in a needs analysis conducted by Cai (2013), students experienced greater difficulty in writing the structure and content of the papers than the language related aspects. Reviewing the previous research studies, designing research methods, and writing the discussion section of the papers were the three most difficult general academic writing skills for students. The same findings were found in Li (2006) and Mirahayuni's (2002) studies.

Articles reviewed by faculties and editors revealed that many submitted articles suffered from lexico-syntactic and discourse problems (Belcher, 2007, Carrio-Pastor \& Mestre-Mestre, 2014; Fazel, 2013; Gea-Valor et al., 2014; Martin et al., 2014). With respect to the lexico-syntactic features of the research articles, Carrio-Pastor and Mestre-Mestre (2014) found that participants made three types of errors: inter-lingual, intra-lingual, and conceptual. Inter-lingual errors occurred as a result of writers' mother tongue. That is, in the case of non-native English speaker (NNES, hereafter) writers, their native language greatly influenced their choice of vocabulary. Intra-lingual errors occurred as a result of participants' deficient knowledge of the second/foreign language, particularly, knowledge of collocations and coinages. Finally, the conceptual errors occurred as a result of writers' misinterpretation of the meaning of words whose forms were similar. Another type of linguistic problems that were frequently found in research articles was related to the discourse features of writing (Belcher, 2007; Carrior-Pastor \& Mestre-Mestre, 2014; Fazel, 2013; GeaValor et al., 2014; Martin et al., 2014). NNES writers' texts were different from native English writers in that they were made of complicated paragraphs with long and wordy sentences. NNES writers used these kinds of sentences in order to express their ideas; despite the fact that academic writing demanded clear and concise language.

Students' perceptions of difficulty in writing different sections of a research paper were also found to be related to disciplinary fields (Moreno et al., 2014). For example, writing the method section was difficult for students in Social Science, Arts, and Humanities than it was for students in Natural and Technological science. Students in Social Science in comparison to those in Arts and Humanities also experienced greater difficulty in writing the abstract section. The discussion section followed by the conclusion and introduction section were perceived to be the most difficult sections to write for students in Social Science and those in Arts and Humanities (Gea-Valor et al., 2014; Moreno et al., 2012; Perez-Llantada et al., 2011). On the other hand, writing references were less problematic for students in Social Science, Arts and Humanities (Cai, 2013). This indicated that EAP programs especially in relation to teaching methods, assessments, and academic goals, in some higher education systems were centered on traditional academic procedures. There was a need to foster critical thinking and critical reading strategies in students through EAP courses. Major reforms in EAP programs were required whereby students, teachers, and EAP curriculum developers could work collaboratively in setting academic goals, engaging in syllabus design, and developing curriculum ((Flowerdew, 1999; Gosden, 1992; Khany \& Tarlani, 2016; Naghdipour, 2016).

\section{Methodology}

\subsection{Design of the Study}

Since we could not find any ready-made measures of the actual academic writing competence (AAWC) and the perceived academic writing competence (PAWC), in Phase 1 theses measures were developed. Second, the factorial validity of the developed measures was assessed with an independent sample using confirmatory factor analysis (CFA). In addition, estimates of internal consistency and convergent and discriminant validity of the measures were also examined. In Phase 2, students' perceptions of academic writing competence was compared with their actual academic performance and whether there were statistically significant differences across different academic groups was explored.

\subsection{Participants}

Data were collected from 391 postgraduate students at private and public universities in Ilam province, Iran. They held either Masters (65.9\%) or Doctorate (34.09 \%) degrees. Participants were recruited trough convenient sampling. That is, sample was chosen from students who were available and willing to participate at the time when the research was being carried out. This method of sampling was selected due to its time and cost effectiveness. Students were 
from nine different academic fields: Agriculture (12.53\%), Mathematics (10.74\%), Architectural Engineering (10.23 $\%)$, Chemistry (9.71 \%), Physics (10.48 \%), Chemical Engineering (11.50 \%), Sociology (9.71\%), Economics (13.29 $\%)$, and Applied Linguistics (11.76\%). The majority of the participants were females (64.2\%). Participants ranged in age from 20 to 35, with an average age of 28.15 years. They were all Iranian; their native language was Persian.

In Phase 2, a total of 210 EAP postgraduate students ( 84 males and 126 females) from the same public and private universities in Ilam province participated. The sample consisted of postgraduate students selected from nine academic fields: $10.47 \%$ were from Agriculture, $14.28 \%$ were from Mathematics, $9.52 \%$ were from Architectural Engineering, $16.66 \%$ were from Chemistry, $11.90 \%$ were from Physics, 9.52 were from Chemical Engineering, $10.47 \%$ were from Sociology, $8.57 \%$ were from Economics, and $8.57 \%$ were from Applied Linguistics. The criterion for assigning students to different proficiency levels was based on their academic levels. Participants' age ranged from 24 to 38 years $(M=26.63, S D=0.73)$. The majority of participants were female $(74.6 \%)$ and the rest were male $(15.2 \%)$.

\subsection{Instruments}

3.3.1 Theoretical Development of the Actual Academic Writing Competence (AAWC) and the Perceived Academic Writing Competence (PAWC)

Within this study, academic writing was defined as including rhetorical, lexical, syntactic knowledge, as well as knowledge of punctuation and mechanics. Insights from systematic functional linguistics by Halliday $(1985,1994)$ provided the theoretical foundation of the construct of academic writing. The theoretical framework also provided the organizing principle for grouping the test items together. The items were classed into four categories including language mechanics, lexical knowledge, syntactic knowledge, and rhetorical knowledge. Knowledge of language mechanics addressed the appropriate use of punctuation marks in writing. Lexical knowledge addressed students' familiarity with specific phraseology and their ability to employ appropriate academic vocabulary in writing. Syntactic knowledge was another component of academic writing that addressed the use of proper grammar and structure and it included aspects such as tense, passive/active voice, and writing coherent and smooth sentences. Finally, rhetorical knowledge was related to students' knowledge of the typical rhetorical organization and conventions of academic research papers (e.g. the IMRD pattern).

\subsubsection{Construction of the AAWC and PAWC}

The measures were developed in four stages. First, each component of academic writing was defined operationally. Second, based on literature and the operational definitions, a large set of items was generated. Third, a panel of experts in the Department of English Language and Literature were asked to determine the content validity of the items on a five-point Likert scale ranging from 1 (lowest) to 5 (highest). They reflected on accuracy, completeness, clarity, and relevance of the items. Based on experts' feedback, items were revised and modified. Next, the items were pilot tested by 83 postgraduate students who were similar in characteristics to the target population for which the questionnaires were constructed. The purpose of the pilot testing was to further gather information on the clarity of the content and the structure of the measures so that they could be used in the second phase of the study. After pilot testing, preliminary factor analyses and reliability analyses were conducted and those items with poorly estimated factor pattern loading and those that reduced the measures' internal consistency were once again revised.

After all these steps, the actual and the perceived academic writing questionnaires, which each was composed four components, were developed (see Appendixes A \& B). The actual measure consisted of 15 items underlying the construct of academic writing: Rhetorical knowledge (6 items), Lexical knowledge, Syntactic knowledge, and Language Mechanics (3 items per each component, respectfully). The perceived academic writing competence (PAWC) questionnaire was a self-report measure assessing students' perceptions of their academic writing knowledge. An initial version of the measure consisted of 33 items: Rhetorical knowledge (11items), Lexical and Syntactic knowledge (9 items per each component, respectfully), and Language Mechanics (4 items). A five-point Likert scale from 1 (Too little) to 5 (Too much) was utilized to indicate students' perceptions regarding their academic writing knowledge. This measure included a number of positively and negatively worded items. For later analyses, these items went through reverse scoring. The items were then translated by the researchers into Persian, the native language of the participants, and proofread and edited by a Ph.D. professor of Persian literature to ensure the accuracy of translation. In addition, back translation was also employed to reduce the transfer effect from English to Persian.

It must be acknowledged that the items included in both measurements were limited in number and nature. For example, in the case of the AAWC measure, items were limited in number because including more items would make 
the test longer (more than 6 pages) which would require more time to complete. Therefore, it would impose on the respondents (Dornyei, 2003). Accordingly, an attempt was made to include items in both measures that at least would represent some important aspects of each component. In Phase 2, the PAWC and AAWC measures were administered. The researchers must acknowledge the limited nature of the items included in both measurements. The PAWC and AAWC measures (in Phase 1) were found to have four components underlying the construct of academic writing. The AAWC measure consisted of Language Mechanics, Lexical, and Syntactic knowledge (3 items, per each component, respectfully), and Rhetorical knowledge (5 items). The PAWC measure comprised Language Mechanics (2 items), Lexical knowledge (4 items), Syntactic knowledge (5 items), and Rhetorical knowledge (10 items).

\subsection{Data Collection Procedure}

Two main sources for data collection were used in the current study: the actual academic writing competence (AAWC) and the perceived academic writing competence (PAWC). Data were collected from graduate students majoring in nine different academic fields of study. The measures were administered by the researchers. After reading the instructions, participants were asked to complete the measures (i.e. the perceived and the actual academic writing competence). They were given unlimited time to provide answers to each item.

\subsection{Data Analysis}

To estimate the reliability of PAWC, Cronbach's alpha was utilized. In order to draw on an independent index for the acceptable level of reliability, a number of studies were consulted. Following Kline (2000) and DeVellis (2012), an estimate of $\alpha \geq .70$ was chosen as an acceptable level of internal consistency of the questionnaire. To estimate the reliability of AAWC, inter-rater reliability was calculated, and then the Spearman-Brown prophecy formula was used to estimate the reliability of the two ratings assigned by two different raters to each student's writing performance. Evidence for the construct validity of the measures was provided through CFA using structural equation modeling (SEM). Structural equation modeling is a multivariate analysis technique used for investigating possible causal relations among variables. SEM can also be used as a confirmatory technique to test whether the data fit the models that are derived from a theory. In the current study, the two models of AAWC and PAWC comprised four latent variables or factors: Factor 1(Language Mechanics), factor 2 (Lexical knowledge), factor 3 (Syntactic knowledge), and factor 4 (Rhetorical knowledge). The observable variables were the items in the questionnaires that were generated for each of the components of academic writing.

In order to test the hypothesized models, AMOS 23 was run and maximum likelihood method was used to estimate the parameters. CFA was conducted on the scores of AAWC and PAWC, separately. For the CFA model, the first of each set of regression paths associated with the factors was set to 1.0 and the items (measured variables) were constrained to load on particular factors. Following suggestions of a number of researchers (Bentler, 1990; Bollen, 1989; Hoyle, 1995; Hu \& Bentler, 1999; Joreskog \& Sorbom, 1999; Sergars \& Grovar, 1993), the following statistics were employed in order to evaluate model fit for confirmatory factor analysis (CFA): $\chi^{2}$, Goodness-of-fit index (GFI), Comparative-Fit Index (CFI), Tucker-Lewis Index (TLI), Root Mean Square Residual (RMR), and Root Mean Square Residual (RMSEA). Compared to other model-fit indexes, less emphasis is placed on the $\chi^{2}$ statistic because it is always large and sensitive to large sample sizes. Generally, the values of GFI, CFI, and TLI statistics range from zero to 1.00 , with values close to 1.00 indicating a good model-fit (Hu \& Bentler, 1999). Values less than .08 and .06 for RMSEA and RMR are considered as good fit indexes.

In Phase 2, actual academic competence of students was calculated, based on an average of students' response scores. The examiners used an analytic scoring rubric to give a final test score. Some of the items were given more weighting than others. In addition, an average score of the items was obtained as an index of perceived academic competence. Furthermore, quantitative analysis of the data was computed using SPSS 21 program. The descriptive statistics such as Mean and Standard Deviation were calculated. One-way MANOVA (Multivariate Analysis of Variance) was run to identify whether differences in writing perceptions and actual performances of the nine EAP groups were statistically significant.

\section{Results}

\subsection{Phase 1}

4.1.1 Confirmatory Factor Analysis Results of AAWC 
The following values (Table 1) were obtained for the proposed model of AAWC, $\chi^{2}(84)=236.465, \mathrm{p}<.0001$, GFI $=$ $.930, \mathrm{CFI}=.912, \mathrm{TLI}=.947, \mathrm{RMSEA}=.046, \mathrm{RMR}=.017$. These values indicated a good fit between the model and the data. Standardized parameter estimates were also provided in Figure 1. Estimated factor loading (see Fig. 1) was all acceptable. Each observed variable or item was shown to be correlated with its theorized factor, while also uncorrelated with another factor. Because of the good model-fit, no post hoc modifications were conducted. On the basis of the results of goodness-of-fit indexes and parameter estimates, the hypothesized four-factor CFA model of actual academic writing competence (AAWC) was confirmed.

Table 1. Selected fit indexes for actual academic writing competence's (AAWC) model

\begin{tabular}{lll}
\hline Fit statistic & Current level & Accepted level \\
\hline$\chi^{2}$ & 236.465 & $p>0.05$ \\
$d f$ & 84 & \\
$\chi^{2}$ significance & .000 & $p<0.05$ \\
GFI & .930 & $>0.90$ \\
CFI & .912 & $>0.90$ \\
TLI & .947 & $>0.90$ \\
RMSEA & .046 & $<0.05$ \\
RMR & .017 & $<0.02$
\end{tabular}

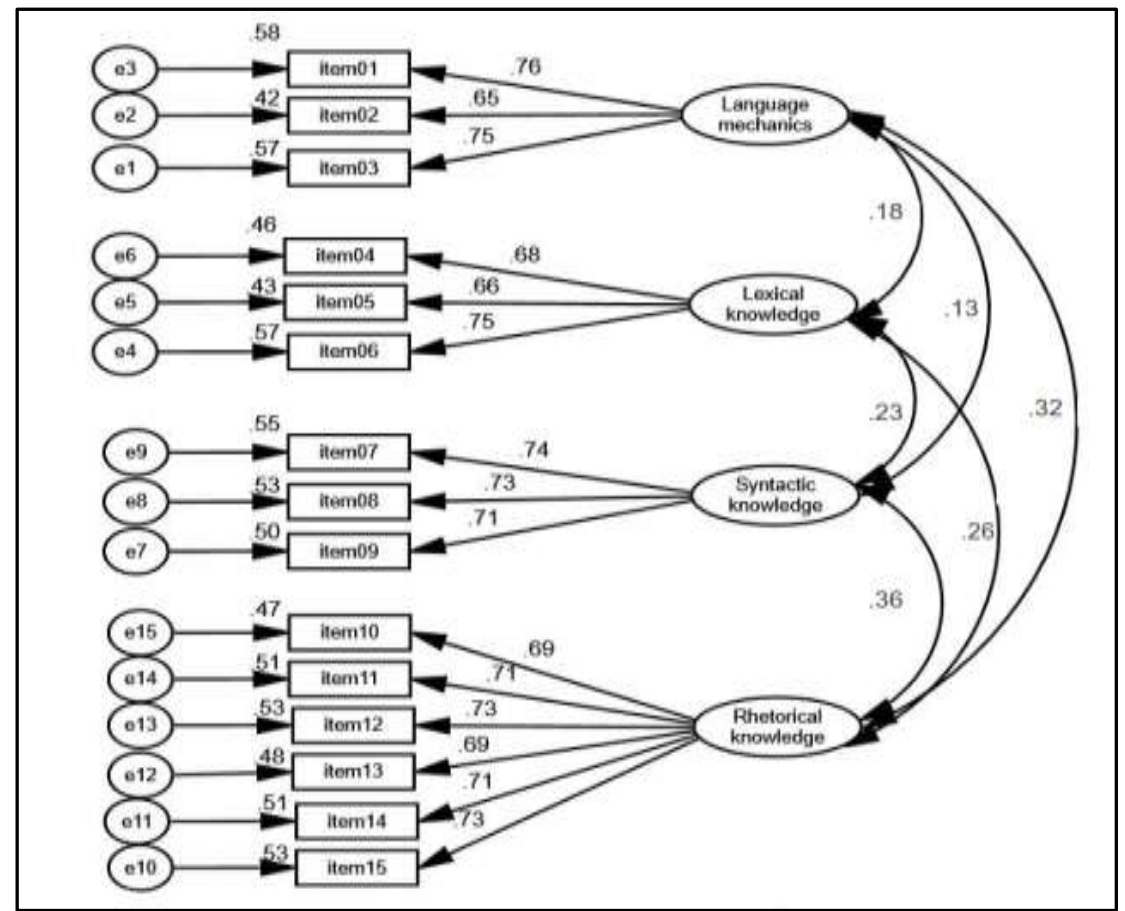

Figure 1. Final model of actual academic writing competence (AAWC)

\subsubsection{Confirmatory Factor Analysis Results of PAWC}

The results of the initial CFA for the PAWC model with 33 items indicated that in general, twelve items had large factor pattern loadings on the incorrect factor. Therefore, the model fit was lower than the desired so these items were 
removed in order to improve the model-fit. Then, another CFA was conducted. The modification indexes were evaluated and indicated that the model fit did significantly improve from a statistical perspective. Figure 2 presents the model of the PAWC factor structure.

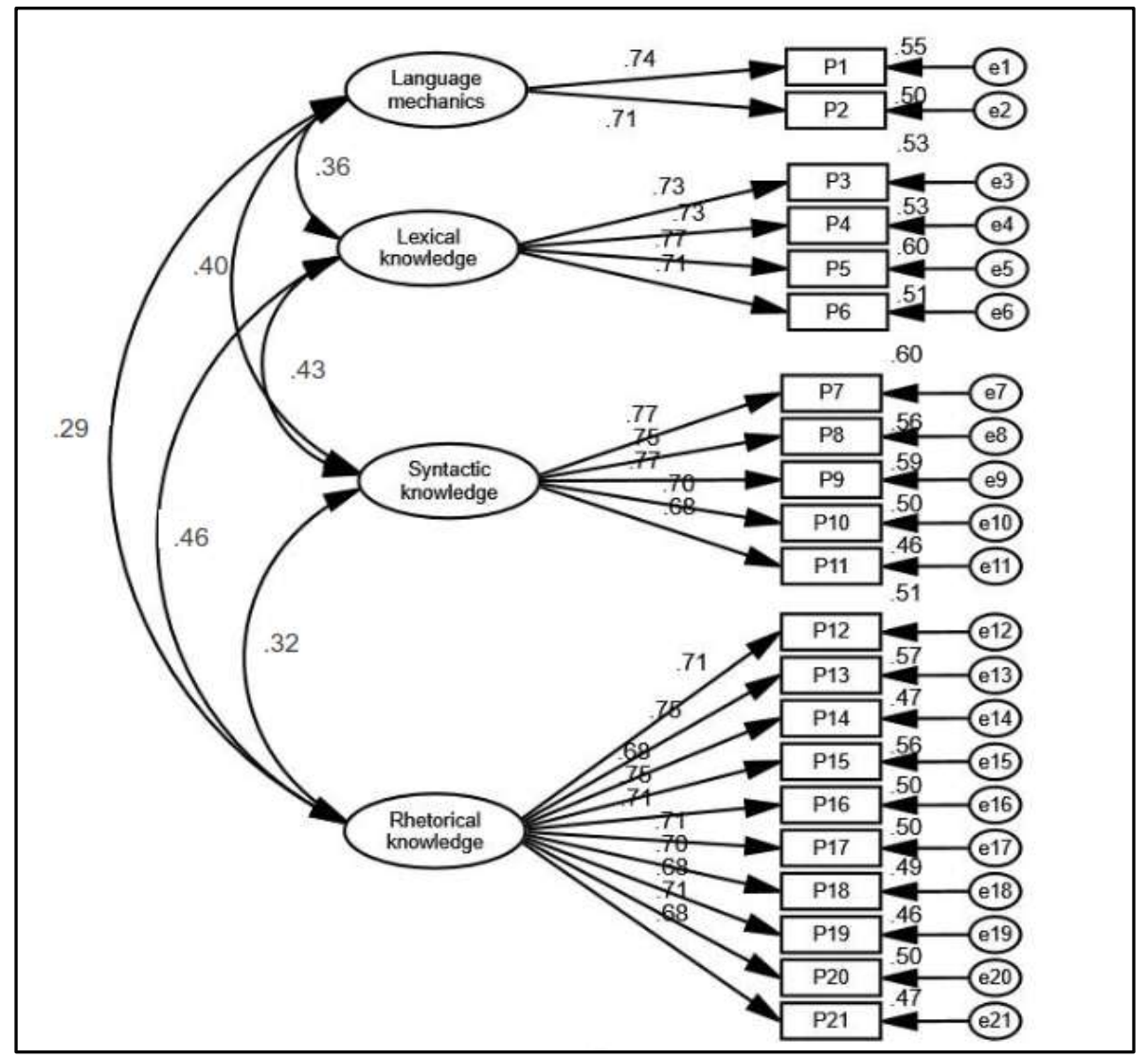

Figure 2. Final model of the perceived academic writing competence (PAWC)

CFA analyses revealed an adequate model fit for the proposed model (see Table 2). The following values were obtained for proposed model of PAWC, $\chi^{2}(264)=369.198, \mathrm{p}<.0001, \mathrm{GFI}=.931, \mathrm{CFI}=.955$, TLI $=.950$, RMSEA $=.035, \mathrm{RMR}=.015$. The fit indexes suggested that the model fitted the data well.

Table 2. Selected fit indexes for the perceived academic writing competence's (PAWC) model

\begin{tabular}{lll}
\hline Fit statistic & Current level & Accepted level \\
\hline$\chi^{2}$ & 369.198 & $p<0.05$ \\
df & 264 & \\
$\chi^{2}$ significance & .000 & \\
GFI & .931 & $>0.90$ \\
CFI & .955 & $>0.90$ \\
TLI & .950 & $>0.90$ \\
RMSEA & .035 & $<0.05$ \\
RMR & .015 & $<0.02$ \\
\end{tabular}


Similar to the AAWC model, estimated factor loadings for PAWC's model (see Fig. 2) were all acceptable. These results suggested that each item was correlated with the theorized factor as indicated by the estimated factor loadings, while also uncorrelated with another factor. The PAWC model also produced a four-factor model with a relatively low inter-factor correlation, suggesting that these factors captured unique information related to the academic writing construct. From a content perspective, these items (see Appendix B) did not appear to be measuring another factor. On the basis of the results of goodness-of-fit indexes and parameter estimates, the hypothesized four-factor CFA model of the perceived academic competence (PAWC) had a good fit with the data; therefore, this model was also confirmed.

\subsubsection{Reliability Analyses}

The internal consistency of the whole PAWC questionnaire estimated through Cronbach's Alpha was 0.83 and for the scores on the four components of academic writing were as follows: Rhetorical knowledge (10 items), $\alpha=.74$, Syntactical Knowledge (5 items), $\alpha=.69$, Lexical Knowledge (4 items), $\alpha=.73$, and Language Mechanics (2 items), $\alpha=.78$. Results for the AAWC measure also showed a good reliability for the 15 items $(\mathrm{a}=.70)$. Overall, these results provided evidence of good internal consistency based on Kline (2000) and DeVellis's (2012) suggestions.

\subsection{Phase 2}

\subsubsection{Research Question 1: EAP Students' Perceptions of their Academic Writing Competence}

To answer the first research question, the respondents were asked to rank their perceptions of the extent to which they think they had competence in general language knowledge and in the maxims and conventions common to writing academic research articles (RAs) on a scale of 1 (too little) to 5 (very much). On the basis of mean scores (Table 3), only small differences existed among the items with no divergent SD scores. The average score of the perceived academic competence with respect to different components of academic writing ranged from a mean of $3.032(\mathrm{SD}=$ 0.762), on "Employing appropriate punctuation and mechanics" item, to a mean of $4.322(\mathrm{SD}=1.052)$ on "Writing a precise and complete abstract" item.

With respect to language-related items including grammar, vocabulary, and punctuation, students reported high perceived competence in academic collocations $(\mathrm{M}=3.974 ; \mathrm{SD}=0.941)$. This was followed by utilizing vocabulary appropriate to the field $(\mathrm{M}=3.965 ; \mathrm{SD}=0.822)$, familiarity with academic vocabulary $(\mathrm{M}=3.922 ; \mathrm{SD}=0.865)$, employing appropriate prepositions $(M=3.821 ; \mathrm{SD}=0.982)$, and familiarity with discourse markers in writing $(\mathrm{M}=$ 3.676; $\mathrm{SD}=0.801)$. As can be seen in Table 3, the lowest mean score was on "Employing appropriate punctuation and mechanics" item $(\mathrm{M}=3.032 ; \mathrm{SD}=0.762)$. This was followed by the knowledge of using correct grammatical structures $(\mathrm{M}=3.301 ; \mathrm{SD}=0.752)$, using correct grammatical tenses $(\mathrm{M}=3.472 ; \mathrm{SD}=0.784)$ and writing coherent sentences $(\mathrm{M}=3.521 ; \mathrm{SD}=0.779)$.

Regarding general conventions of RAs, respondents reported having competence in three main sections. They demonstrated a high level of awareness in writing a precise and complete abstract $(\mathrm{M}=4.322 ; \mathrm{SD}=1.052)$ followed by writing the introduction section $(\mathrm{M}=4.313$; $\mathrm{SD}=1.012)$. The lowest mean score was on "Critical review of relevant studies" item $(\mathrm{M}=3.985 ; \mathrm{SD}=1.118)$ followed by discussing the results of the study $(\mathrm{M}=3.992 ; \mathrm{SD}=$ 1.053). 
Table 3. EAP students' mean score on the perceived academic writing questionnaire (PAWC)

\begin{tabular}{|c|c|c|c|c|}
\hline & No & Question item & $\mathbf{M}$ & SD \\
\hline \multirow{3}{*}{ 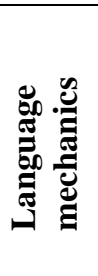 } & 1,2 & Familiarity with and the use of appropriate & 3.012 & .0756 \\
\hline & & punctuation marks and mechanics in writing & 3.032 & 0.762 \\
\hline & 3 & Employing appropriate prepositions & 3.821 & 0.982 \\
\hline \multirow{4}{*}{ 窇 } & 4 & Familiarity with academic vocabulary & 3.922 & 0.865 \\
\hline & 5 & Utilizing vocabulary appropriate to the field & 3.965 & 0.822 \\
\hline & 6 & Familiarity with academic collocations & 3.974 & 0.941 \\
\hline & 7,8 & Using correct grammatical structures & 3.301 & 0.752 \\
\hline \multirow{4}{*}{ 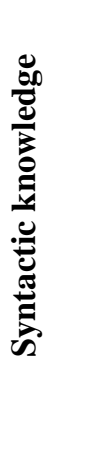 } & 9 & Using correct grammatical tenses & 3.472 & 0.784 \\
\hline & 10 & Achieving coherence among sentences & 3.521 & 0.779 \\
\hline & 11 & Familiarity with discourse markers in writing & 3.676 & 0.801 \\
\hline & 12 & & 4.254 & 1.045 \\
\hline \multirow{10}{*}{ 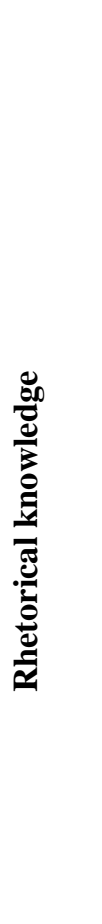 } & & Writing a brief and eye-catching title & & \\
\hline & 13 & Writing a precise and complete abstract & 4.322 & 1.052 \\
\hline & 14 & writing the introduction section & 4.313 & 1.012 \\
\hline & 15 & Presenting theoretical basis of the topic & 4.288 & 1.243 \\
\hline & 16 & Critical review of relevant studies & 3.985 & 1.118 \\
\hline & 17 & $\begin{array}{l}\text { Selecting methodology compatible with research } \\
\text { design }\end{array}$ & 4.164 & 1.071 \\
\hline & 18 & Employing statistics consistent with collected data & 4.110 & 1.085 \\
\hline & 19 & Statistical analysis of data & 4.207 & 1.096 \\
\hline & 20 & Presenting the results of the study & 4.223 & 1.321 \\
\hline & 21 & Discussing the obtained results & 3.992 & 1.053 \\
\hline
\end{tabular}

Note. $\mathrm{M}=$ Mean; $\mathrm{SD}=$ Standard deviation 


\subsubsection{Research Question 2: EAP Students’ Actual Academic Writing Performance}

Students demonstrated a low level of performance on most of the items of actual academic writing competence measure on the basis of Mean scores obtained for each item. There were minor differences in performance among postgraduates of different academic fields. In comparison to other RAs' sections, students achieved the lowest mean score on items concerning "Writing a complete and precise abstract" $(M=1.002 ; S D=0.981)$, "Observing moves in writing RAs' abstracts" $(M=1.124 ; S D=0.986)$, and "Observing moves in writing RAs' sections" $(M=1.136 ; S D$ $=0.974)$. On the other hand, they achieved the highest scores on items concerning "Presenting results in tables, graphs, etc." $(M=1.395 ; S D=0.961)$ "Utilizing common reference style of academic RA" $(M=1.388 ; S D=0.883)$, and "Reporting the results" $(M=1.379 ; S D=0.967)$. Concerning language-related items, the respondents generally performed the least well on items related to punctuation and vocabulary. The participants had the lowest performance in choosing a correct academic vocabulary when writing RAs $(M=1.241 ; S D=0.721)$. This was followed by knowledge of appropriate punctuation and mechanics $(M=1.254 ; S D=0.752)$. In contrast, they performed well on items related to syntactic knowledge. The mean scores on these items ranged from $1.374(S D=0.788)$ to $1.385(S D=$ 0.770).

Table 4. EAP students' mean score on actual academic writing questionnaire (AAWC)

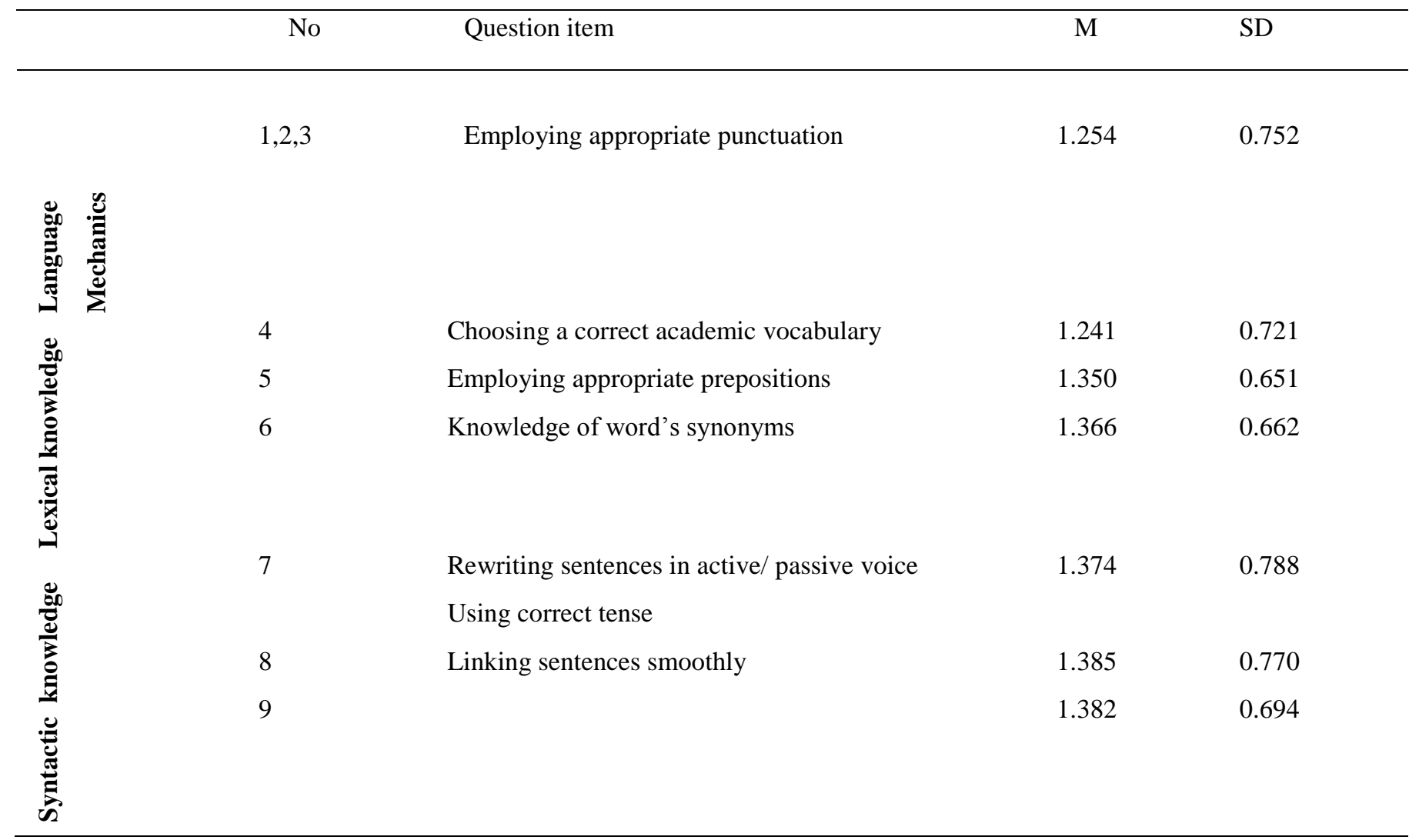




$\begin{array}{lllll}10 & \text { Writing a complete and precise abstract } & 1.002 & 0.981 \\ 11 & \text { Reporting the results } & 1.379 & 0.967 \\ & 12 & \text { Observing moves in writing RAs' abstracts } & 1.124 & 0.986 \\ & \text { Utilizing common reference style } & & \\ & & & 1.388 & 0.883 \\ 13 & \text { Observing moves in writing RAs' sections } & 1.136 & 0.974 \\ 15 & \text { Presenting results in tables, graphs, etc. } & 1.395 & 0.961\end{array}$

Note. $\mathrm{M}=$ Mean; $\mathrm{SD}=$ Standard deviation

4.2.3 Research Question 3: EAP Postgraduate Students' Actual and Perceived Academic Writing Competence

Table 5 presents the general performance of EAP students on the perceived and actual academic writing competence instruments. To examine whether there was any statistically significant difference in students' perceptions and actual performances with reference to their academic fields, One-way MANOVA was run. As Table 6 shows, the level of significance was 0.0254 , at $\mathrm{p}<.05$ value. Thus, there seems to be a statistically significant difference in academic writing perceptions and actual performances of postgraduate students across different academic fields.

Table 5. Descriptive statistics of the actual and perceived academic writing competence across nine EAP groups

Perceived academic competence Actual academic competence

\begin{tabular}{llccc}
\cline { 2 - 4 } & $\mathrm{M}$ & $\mathrm{SD}$ & $\mathrm{M}$ & $\mathrm{SD}$ \\
\hline Agriculture & 8.46 & 1.574 & 2.470 & 1.970 \\
Mathematics & 8.63 & 1.766 & 3.514 & 1.581 \\
Architectural Engineering & 7.515 & 1.477 & 2.654 & 1.922 \\
Chemistry & 7.320 & 1.342 & 2.331 & 1.861 \\
Physics & 7.861 & 1.858 & 3.12 & 0.873 \\
Chemical Engineering & 8.962 & 1.483 & 3.001 & 1.733 \\
Sociology & 8.752 & 1.490 & 2.707 & 1.015 \\
Economics & 9.253 & 1.591 & 2.445 & 1.042 \\
Applied Linguistics & 9.513 & 1.790 & 2.960 & 0.997 \\
\hline
\end{tabular}

Note. $\mathrm{M}=$ Mean; $\mathrm{SD}=$ Standard deviation. 
Table 6. Multivariate test's results

\begin{tabular}{lcclccccc}
\hline Effect & Value & F & Hypothesis df & Error df & Sig & $\begin{array}{l}\text { Partial Eta } \\
\text { Squared }\end{array}$ & $\begin{array}{l}\text { Noncent. } \\
\text { Parameter }\end{array}$ & $\begin{array}{l}\text { Observed } \\
\text { Power }^{b}\end{array}$ \\
\hline Pillai's Trace & .412 & 10.512 & 9.000 & 28.000 & .0154 & .105 & 32.055 & .989 \\
Wilks' Lambda & .074 & 8.636 & 9.000 & 24.000 & .0254 & .126 & 29.125 & .965 \\
Hotelling's Trace & 0.098 & 11.789 & 9.000 & 18.000 & .325 & .324 & 20.058 & .825 \\
$\begin{array}{l}\text { Roy's Largest } \\
\text { Root }\end{array}$ & .124 & 13.512 & 7.000 & 20.000 & .0658 & .148 & 25.369 & .789 \\
\hline
\end{tabular}

\section{Discussion}

This study found convincing evidence for the reliability and validity of the scores obtained from the AAWC and PAWC measures. Findings from CFA confirmed that the AAWC and PAWC scores have four distinct factors that were labeled as Language Mechanics, Lexical, Syntactic, and Rhetorical knowledge. The developed measures provided good factorial validity evidence based on the good model fit and estimated factor pattern loadings. Based on the good model fit, these results provided evidence of good factorial validity. Each item was highly correlated with its corresponding factor (See Fig $1 \& 2$ ). All the estimated factor loadings were greater than 0.60. In addition, strong discriminate validity was observed among the four factors, as the four factors were not highly correlated (i.e. correlations below .50).

The results of Phase 1 are valuable as the development of the AAWC and PAWC is a step toward clarifying academic writing practices of EAP students. These newly developed instruments may add to the current body of research on academic writing because there is limited existing literature on students' actual academic performances in comparison to their perceptions. Although literature sheds lights on students' perceptions regarding their writing competence, a few research studies can be found about their actual performances.

Findings from descriptive analyses (Tables $3 \& 4$ ) revealed that students' perception regarding their academic writing competence was quite different from their actual academic competence. In the present study, students perceived their knowledge of lexical and syntactic aspects of academic writing to be the highest. However, in other research studies (e.g. Hinkel, 2003; Li, 2006; Shaw \& Liu, 1998; Zhang, 2011) postgraduate students found the language-related aspects of academic writing such as word choices, sentence structures, and grammar to be difficult. Evans and Green (2007) also found that participants found it difficult to build accurate and smooth sentences while writing academically. In contrast, Cai (2013) suggested that students expressed greater difficulty in content-related matters of writing. To those students, reviewing and critiquing previous research studies, designing an appropriate research method, and discussing the obtained results were the most difficult parts of research articles (RAs).

In the current study, students perceived themselves to be very competent in writing the abstract and the introduction sections. However, they had the lowest performance on items related to observing the moves and sub-moves common to writing the abstract and the introduction sections. Students perceived having less knowledge in writing the literature review section. This finding was in line with the findings of Li's (2006) study, where non-native English writers also experienced difficulty in conducting a precise and thorough literature review. The fact that writing this section was perceived difficult for students may suggest that they might have lacked the ability in providing a meticulous and critical review of previous research (Li, 2006; Mirahayuni, 2002).

It can also indicate a need to promote critical thinking and critical reading strategies in students through courses so that they can develop such abilities. Moreover, in order to foster more critical students, Iranian academic settings should empower students by getting them involved in exercises and activities targeted at developing critical skills. Students need to be engaged in intellectual discussions and they need to have an active role in determining academic and educational objectives by asking questions and giving opinions and suggestions (Khany \& Tarlani, 2016). Furthermore, the respondents in the current study perceived having little competence in discussing the findings of the study. This can be an indicator of students' lack of argumentative ability to discuss, analyze, and make claims on the 
findings (Flowerdew, 1999; Gosden, 1992). These issues should also be addressed in EAP programs in the educational system of Iran.

The findings of the present study suggested that special attention must be directed to language-related aspects of writing. The literature on EFL/ESP programs in Iranian settings has shown that EAP/ESP students' level of general English proficiency is low despite the fact that they receive a course in general English even before their subjectspecific English course (Alavi \& Tahririan, 1996; Atai, 2000; Tahririan, 1987). Furthermore, it has been revealed that Iranian EAP/ESP students lack sufficient language skills (i.e. reading, listening, speaking, and writing) and need to be offered specialized English courses in order to develop sufficient academic abilities (Mazdayasna \& Tahrririan, 2008). Particularly, English writing skills need to be more emphasized for EAP Iranian students at university levels because, in the context of Iran, students face a truncated English language curriculum that leads to underdeveloped writing skills (Naghdipour, 2016).

In Iranian EAP contexts, the focus is on fostering students' reading comprehension abilities and on increasing vocabulary knowledge. Other skills, especially, writing skill receives less attention. Therefore, students should receive instruction through which general academic writing skills can be transferred to them so that they could deal with writing tasks. However, the transfer of such skills entails the involvement of both content and writing instructors. Writing language instructors are required to teach students the basic writing skills; content instructors, on the other hand, are needed to teach discipline-specific writing skills. This collaboration between writing instructors and subjectspecific instructors will provide students with general as well as subject specific writing skills. Furthermore, there is an urgent need to shift to more communicative approach to teach RA writing, where writing is viewed as a communicative activity shaped by its context.

\section{Implications}

The results of this study will add to the body of knowledge about academic writing by shedding light on the perceptions of students compared to their actual writing competence. The results of the study revealed aspects of academic writing that are more challenging and in need of more attention for EAP/EFL students. Particularly, results of the study are beneficial for EAP students to become aware of their weaknesses in writing academically, and be prepared to focus more on increasing and improving their necessary academic knowledge and abilities since it was shown that the performance of students was at odd with their perceptions. Besides, suitable content of an EAP courses and EAP curriculum can be designed based on the results of the present study. Particularly, when identifying suitable EAP curriculum and pedagogy, special attention must be paid to the sociocultural context. It is revealed that Iranian EAP students have much less knowledge of genres of academic writing in higher education (Naghdipour, 2016). A reformed EAP educational system could help students in Iran and other countries who have problems in academic writing in higher education.

\section{Conclusion}

This study was a preliminary attempt to investigate Iranian postgraduate students' perceptions and actual performances with respect to writing academic research articles for publication. The two phases of the present study addressed different aspects of students' academic writing competence. Students' high ratings on the perceived academic writing questionnaire suggested that they perceived themselves to have the necessary academic knowledge to write academically. The results of the actual academic performance of students revealed that students had low competencies in language- as well as content-related items. EAP students, teacher development, and EAP course designers can benefit from the results of this study. The results are beneficial for EAP students by shedding light on aspects of academic writing that are more challenging and in need of more attention. Students can become aware of their weaknesses in writing academically, and be prepared to focus more on increasing and improving the necessary academic knowledge and abilities.

In addition, through identifying students' academic needs, EAP teachers can also create opportunities for students to engage in real academic activities and exercises that they may need in the future. They can also explain the goals and objectives of academic writing. The results are also beneficial for EAP course designers in helping them identify and develop suitable curriculum content for EAP pedagogy and EAP courses. For example, EAP course designers can develop a task-based pedagogy that addresses specific language features and steps of academic writing accompanied with rich classroom discussions. To our knowledge, this is the first study that has been conducted in Iranian higher education EAP setting. It focused on one particular academic EAP context with a particular group of students. 
Therefore, care should be taken before generalizing the findings of the current study to other Iranian higher educational EAP contexts. In addition, only limited type and numbers of items were included in the newly developed measurements. Therefore, future research studies may include other types of items that tap into different aspects of academic writing.

\section{References}

Alavi, S., \& Tahririan, M. H. (1996). EFL learners' proficiency and their performance on GPE and ESP collocations. Indian Journal of Applied Linguistics, 22(2), 23-41.

Al-Badwawi, H. S. Q. (2011). The perceptions and practices of first-year students' academic writing at the Colleges of Applied Sciences in Oman. The University of Leeds. https://etheses. whiterose.ac.uk/id/eprint/2390

Atai, M. R. (2000). ESP revisited: a reappraisal study of discipline-based EAP programs in Iran. Unpublished Ph.D. dissertation, University of Isfahan, Isfahan, Iran.

Badley, G. (2009). Academic writing as shaping and re-shaping. Teaching in Higher Education, 14(2), 209-219. doi: $10.1080 / 13562510902757294$

Bardi, M. (2015). Learning the practice of scholarly publication in English: A Romanian perspective. Online Journal, 37(2), 98-111. http://dx.doi.org/10.1016/j.esp.2014.08.002

Belcher, D. D. (2007). Seeking acceptance in an English-only research world. Journal of Second Language Writing, 16(3), 1-22. doi:10.1016/j.jslw.2006.12.001

Bentler, P. M. (1990). Comparative fit indexes in structural models. Psychological Bulletin, 107(2), 238-251. https://escholarship.org/uc/item/6cn677bx

Bocanegra-Valle, A. (2014). English is my default academic language: Voice from LSP scholars publishing in a multilingual journal. Journal of English for Academic Purposes, 13(2), 65-77. https://doi.org/10.1016/j.jeap.2013.10.010

Bollen, K. A. (1989). A new incremental fit index for general structural equation models. Sociological Methods \& Research, 17(3), 303-316. doi: 10.1177/0049124189017003004

Cai, L. J. (2013). Students' perceptions of academic writing: A needs analysis of EAP in China. Language Education in Asia, 4(1), 5-22. https://doi.org/10.5746/LEiA/13/V4/I1/A2/Cai

Carrio-Pastor, M., \& Mestre-Mestre, E. (2014). Lexical errors in second language scientific writing: Some conceptual implications. International journal of English studies, 14(1), 21-45. doi: https://doi.org/10.6018/ijes/14/1/154361

DeVellis, R. F. (2016). Scale development: Theory and applications (Vol. 26). Sage publications.

Dörnyei, Z. (2003). Questionnaires in second language research: Constructing, administering, and processing. Lawrence Erlbaum Associates.

Evans, S., \& Green, C. (2007). Why EAP is necessary: A survey of Hong Kong tertiary students. Journal of English for Academic Purposes, 6(1), 3-17. https://doi.org/10.1016/j.jeap.2006.11.005

Fazel, I. (2013). Writing for journal publication: An overview of NNES challenges and strategies. Pan-Pacific Association of Applied Linguistics, 17(2), 95-114.

Flowerdew, J. (1999). Problems in writing for scholarly publication in English: The case of Hong Kong. Journal of Second Language Writing, 8(3), 243-264. https://doi.org/10.1016/S1060-3743(99)80116-7

Gea-Valor, M. L., Rey-Rocha, J., \& Moreno, I. A. (2014). Publishing research in an international context: An analysis of Spanish scholars' academic writing needs in the social sciences. English for Specific Purposes, 36(2), 4757. https://doi.org/10.1016/j.esp.2014.05.001

Gosden, H. (1992). Research writing and NNSs: From the editors. Journal of Second Language Writing, 1(2), 123139. https://doi.org/10.1016/1060-3743(92)90012-E 
Halliday, M. A. (1985). An introduction to functional grammar. London: Edward Arnold.

Halliday, M. A. (1994). Functional grammar. London: Edward Arnold.

Hanauer, I. D., \& Englander, K. (2011). Quantifying the burden of writing research articles in a second language: Data from Mexican scientists. Written Communication, 27(3), 1-14. doi: 10.1177/0741088311420056

Hinkel, E. (2003). Teaching academic ESL writing: Practical techniques in vocabulary and grammar. Routledge.

Hoyle, R. H. (1995). Structural equation modeling: Concepts, issues, and applications. Sage Publications.

Hu, L. T., \& Bentler, P. M. (1999). Cutoff criteria for fit indexes in covariance structure analysis: Conventional criteria versus new alternatives. Structural equation modeling: A multidisciplinary journal, 6(1), 1-55. https://www.sid.ir/En/Journal/ViewPaper.aspx?ID=98854

Jalongo, M. R. (2013). Getting on the conference program and writing a practical article: Templates for success. Early Childhood Education Journal, 41(1), 13-23. https://doi.org/10.1007/s10643-012-0533-x

Joreskog, K. G., \& Sorbom, D. (1999). LISREL 8.30. Chicago: Scientific Software International.

Khany, R., \& Tarlani-Aliabadi, H. (2016). Studying power relations in an academic setting: Teachers' and students' perceptions of EAP classes in Iran. Journal of English for Academic Purposes, 21(2), 72-85. https://doi.org/10.1016/j.jeap.2015.12.002

Kline, R. B. (2000). Principles and practice of structural equation modeling. Guilford Publications.

Lee, S. C. N., \& Tajino, A. (2008). Understanding students' perceptions of difficulty with academic writing for teacher development: A case study of the university of Tokyo writing program. Journal of English for Academic Purposes, 13(2), 42-55.

Li, Y. (2006). A doctoral student of physics writing for publication: A sociopolitically-oriented case study. English for Specific Purposes, 25(4), 456-478. https://doi.org/10.1016/j.esp.2005.12.002

Maher, A. M., Feldon, F. D., Timmerman, E. B., \& Chao, J. (2014). Faculty perceptions of common challenges encountered by novice doctoral writers. Higher Education Research \& Development, 33(1), 699-711.

Martin, P., Rey-Rocha, J., Burgess, S., \& Moreno, I. A. (2014). Publishing research in English-language journals: Attitudes, strategies, and difficulties of multilingual scholars of medicine. Journal of English for Academic Purposes, 16(1), 57-67. https://doi.org/10.1016/j.jeap.2014.08.001

Mazdayasna, G., \& Tahririan, M. H. (2008). Developing a profile of the ESP needs of Iranian students: The case of students of nursing and midwifery. Journal of English for Academic Purposes, 7(4), 277-289. https://doi.org/10.1016/j.jeap.2008.10.008

Mirahayuni, N. K. (2002). Investigating textual structure in native and non-native English Research articles: Strategy differences between English and Indonesian writers. University of New South Wales.

Moreno, A., Rey-Rocha, J., Burgess, S., Lopez-Navarro, I., \& Sachdev, I. (2012). Spanish researchers' perceived difficulty writing research articles for English- medium journal: The impact of proficiency in English versus publication experience. Iberica, 24(3), 157-184.

Naghdipour, B. (2016). English writing instruction in Iran: Implications for second language writing curriculum and pedagogy. Journal of Second Language Writing, 32(1), 81-87. https://doi.org/10.1016/j.jslw.2016.05.001

Perez-Llantada, C., Plo, R., \& Ferguson, R. G. (2011). You don't say what you know, only what you can: The perceptions and practices of senior Spanish academics regarding research dissemination in English. English for Specific Purposes, 30(3), 18-30. doi:10.1016/j.esp.2010.05.001

Segars, A. H., \& Grover, V. (1993). Re-examining perceived ease of use and usefulness: A Confirmatory factor analysis. MIS quarterly, 17(4) 517-525. doi: 10.2307/249590 https://www.jstor.org/stable/249590

Shaw, P., \& Liu, E. T. K. (1998). What develops in the development of second-language writing? Applied linguistics, 19(2), 225-254. https://doi.org/10.1093/applin/19.2.225 
Tahririan, M. H. (1987). ESP, yes, but for what learners. IAPE, Esfahan, 3.

Wilkinson, A. (2015). The rules of the game: A short guide for PhD students and new academics on publishing in academic journals. Innovations in Education and Teaching International, 52(1), 99-107. doi:10.1080/14703297.2014.978350

Zhang, Z. (2011). A nested model of academic writing approaches: Chinese international graduate students' views of English academic writing. Language and Literacy, 13(1), 39-59. doi: https://doi.org/10.20360/G27G6R 


\section{Appendix A}

\section{Actual Academic Writing Competence Measure}

This questionnaire is part of academic research. Your cooperation will aid the research. The researcher promises to maintain strict confidentiality of your information. Please provide answers to the following questions.

\section{Edit the following passage by adding appropriate punctuation mark.}

A primary finding from this work is that students typically do not leave STEM majors for academic or financial reasons__ rather__ students are leaving STEM majors as a result of poor mathematics and science instruction __ most specifically_ poor calculus instruction is often cited as the primary reason

\section{Rewrite the following sentences using any punctuation mark necessary correctly.}

a) Different explanations for the scarce understanding of quadratic equations have been suggested

b) S'onnerhead, for example, noticed that mathematics textbooks in Sweden omit important concepts that would not be presented by many teachers thus students will tend to develop a disconnected and incomplete set of ideas regarding quadratic equations

\section{3. "Local governments urge the residents of some cities of the United States to use water conservatively otherwise there wotl be enough water for everyone"} What correction, in terms of punctuation should be made to this sentence?

\section{Write a verb that reduces the informality of each sentence.}

a. This empirical study can $\underline{\text { help out }}$ to investigate Calculus I programs across the United States-

b. It is set up to better understand the relationship between instructors' concerns about coverage, instructional practices, and the nature of the material covered-

c. Our results $\underline{s a y}$ that both intended pacing and feelings of pressure are poor indicators of instructional practices-----

\section{Fill in the blank with an appropriate preposition.}

1. As can be seen Table 4, concerns about coverage did not differ significantly among instructors at selected and non-selected institutions.

2. These results, aggregated by practice and nature of institution, can be found ------- Table1.

3. As shown ------- Table 3, the majority of instructors from non-selected institutions reported high frequencies of showing students how to work specific problems.

\section{Write the synonym of the underlined word.}

"The results imply that gender, age, and teaching experiences did not influence the teachers' perceptions of teacher leadership practice."

\section{Rewrite these sentences to put them in the passive voice.}

a. We conducted one-way analysis of variance by ranks for each of the eight instructional practices.

b. These reports were statistically significant.

c. After administering the questionnaires, the researcher computed descriptive and inferential statistics to analyze the collected data.

\section{Write the correct form of the verb in the parantheses.}

The present study 1........... (explore) possible associations between students'perceptions of a writing prompt and their actual writing performance on a field-specific (FS) English for academic purposes (EAP) writing test. Each of the 124 students 2.............( produce) two writing samples.The subjects'performances on the two tests 
3...............( compare) across the four prompt subgroups. It 4 . (find) that students' performances were not statistically different from the two different tests or across the prompts chosen on the FS EAP writing test.

9. Supply linking words or phrases that enhance the flow of the passage.

As an individual needs to perform actions on a process, he/she may become aware of the process as a totality, an entity in itself. ........ the individual can perform or imagine performing actions on the process, it is said the process has been encapsulated into an Object. An object may be de-encapsulated into the process and actions it came from as needed in a problem situation. .........., a student having an object conception of quadratic formula can be expected to be able to use it if necessary, without prompt, and in any context.

10. Write an abstract (150 words) on one of the following topics:

a) Strengthening Food and Natural Resources Technology and Policy for Sustainable Agriculture

b) Role of Self-Efficacy in Reducing Residential Energy Usage

c) The effect of a special program of vocabulary instruction on social studies achievement

d) A Novel Fluorescent Sensor for the Sensitive Detection of Mercury

e) Quantitative measurement of metal chelation by Fourier transform infrared spectroscopy

f) Utilitarian population ethics and births timing

g) Improved critical thinking in students using current events journaling

h) It's about time: the relationships between coverage and instructional practices in college calculus.

k) Write on your own choice.

11. The Table below gives information about the results from science and engineering students in multivariable calculus. The results from this group of students are based solely on their written response to the two questions above. These questions mainly test student understanding of properties SR1 (square root) and SR2.

Report the results by selecting and reporting the main features, and make comparisons where relevant (Write at least 150 words).

\begin{tabular}{l|l|l|l}
\hline $\begin{array}{l}\text { Total number } \\
\text { of students }\end{array}$ & $\begin{array}{l}\text { Correct use of } \\
\text { processes in SR1 } \\
\text { and SR2 }\end{array}$ & $\begin{array}{l}\text { Incorrect use of } \\
\text { processes in } \\
\text { SR*1 and SR2 }\end{array}$ & $\begin{array}{l}\text { No use of } \\
\text { processes in SR1 } \\
\text { and SR2 }\end{array}$ \\
\end{tabular}

$\begin{array}{lllll}\text { Question 1 } & 121 & 18(14.9 \%) & 53(43.8 \%) & 50(41.3 \%) \\ \text { Question 2 } & 121 & 20(16.5 \%) & 40(33.1 \%) & 61(50.4 \%)\end{array}$

\section{*square root}

12. The following is an abstract from the journal of Mathematics. It does not follow the standard order of the abstract section. Arrange the sentences to form an appropriate abstract.

(A) An unstructured oral interview followed (B) Although no significant difference was found between the students' assessments and the instructors' actual assessments, students perceived the instructors' assessments to be stricter than their own. $(\boldsymbol{C})$ This study explores the perceptions of different groups of L1 and L2 Israeli pre-service teachers and their instructors regarding good academic writing. (D) Results indicated that guidelines and instruction in academic writing enabled students to accommodate their instructor's demands and to assess academic text. 


\section{Choose the most appropriate reference in the following items:}

a) Lee, J. (1986). On the use of recall task to measure L2 reading comprehension. Studies in Second Language Acquisition, 8, 83-93.

b) Lee, J. On the use of recall task to measure L2 reading comprehension (1986). Studies in Second Language Acquisition, 8, 83-93.

c) On the use of recall task to measure L2 reading comprehension. Lee, J. (1986). Studies in Second Language Acquisition, 8, 83-93.

d) Studies in Second Language Acquisition, 8, 83-93. Lee, J. (1986). On the use of recall task to measure L2 reading comprehension.

14. Indicate in which section of a journal article reporting quantitative research (introduction, methods) the following statements would belong:

a. "For this report, we narrow our focus to $\mathrm{PhD}$-granting universities and consider two populations of instructors: those at institutions that were selected based on the success of their calculus programs and those at institutions that were not selected."

b. "This paper is based on a large-scale empirical study designed to investigate Calculus I programs across the United States to better understand the relationship between instructors' concerns about coverage, instructional practices, and the nature of the material covered"

c. "Our results indicate that both intended pacing and feelings of pressure are actually poor indicators of instructional practices."

15. Assume you have conducted a research on "Relationship between concerns about coverage and instructional practices". You obtained the following results:

The majority (60\%) of instructors from non-selected institutions report holding whole-class discussions with low frequency and an overwhelming majority (85\%) report lecturing with high frequency - regardless of the reported amount of pressure they were feeling to cover material quickly. At the non-selected institutions, all the instructors who re-ported high pressure had students present at low frequency, while among instructors who reported low or medium pressure, $85.7 \%$ had students present at low frequency. How-ever, it should be noted that only $1.9 \%$ of the instructors reported a high frequency of student presentation, so this is not a widely reported teaching practice in either case.

Use a table or a pie chart to present these findings so that they could be more readily comprehended by readers. 


\section{Appendix B}

\section{The Perceived Academic Writing Competence Questionnaire}

The purpose of this study is to investigate your perceptions of your academic writing. Please choose one of the options.

1. To what extent are you familiar with punctuation and mechanics of English language in writing research articles for publication?
Too much
Much
Fair
little
Too Little

2. To what extent do you think you use inappropriate punctuation when writing?

$\begin{array}{llll}\text { Too much } & \text { Much } & \text { Fair } & \text { little }\end{array}$

3. To what extent do you regard yourself able at selecting appropriate prepositions?
Too much
Much
Fair
little
Too Little

4. To what extent do you think that you are unfamiliar with common academic vocabulary in your field?

$\begin{array}{llll}\text { Too much } & \text { Much } & \text { Fair } & \text { little }\end{array}$

5. How would you evaluate your knowledge in utilizing appropriate and relevant vocabulary?
Too much
Much
Fair
little
Too Little

6. To what extent are you unfamiliar with academic collocations?

$\begin{array}{llll}\text { Too much } & \text { Much } & \text { Fair } & \text { little }\end{array}$

7. To what extent are you familiar with basic sentence structures?

$\begin{array}{llll}\text { Too much } & \text { Much } & \text { Fair } & \text { little }\end{array}$

8. To what extent are you familiar with complex and compound sentence structures?

$\begin{array}{llll}\text { Too much } & \text { Much } & \text { Fair } & \text { little }\end{array}$

9. How would you evaluate your knowledge of passive/active tense?

$\begin{array}{lllll}\text { Too much } & \text { Much } & \text { Fair } & \text { little }\end{array}$

10. How would you evaluate your knowledge in writing coherent sentences?
Too much
Much
Fair
little
Too Little

11. To what extent do you think you are unfamiliar with discourse and metadiscourse markers?

$\begin{array}{llll}\text { Too much } & \text { Much } & \text { Fair } & \text { little }\end{array}$

12. How would you evaluate your ability in writing an eye-catching topic for your research?

$\begin{array}{llll}\text { Too much } & \text { Much } & \text { Fair } & \text { little }\end{array}$

13. To what extent are you familiar with generic moves in writing the abstract section of research papers?

$\begin{array}{llll}\text { Too much } & \text { Much } & \text { Fair } & \text { little }\end{array}$

14. To what extent do you think you include irrelevant or redundant content in the introduction section of the article?

$\begin{array}{llll}\text { Too much } & \text { Much } & \text { Fair } & \text { little }\end{array}$

15. How do you evaluate your ability in describing theoretical basis of your research study?
Too much
Much
Fair
little
Too Little

16. When writing the literature review, how well do you think you are at critically reviewing the related studies?
Too much
Much
Fair
little
Too Little 
17. To what extent are you unfamiliar with different research methodologies?

Too much Much Fair little Too Little

18. To what extent are you familiar with different statistical techniques?

$\begin{array}{llll}\text { Too much } & \text { Much } & \text { Fair } & \text { little }\end{array}$

19. How do you rate your ability in analyzing the obtained data?
Too much
Much
Fair
little
Too Little

20. In writing the Results section, how do you evaluate your ability in summarizing the data presented in tables or figures?

$\begin{array}{llll}\text { Too much } & \text { Much } & \text { Fair little } & \text { Too Little }\end{array}$

21. How do you evaluate your ability in discussing the results of the study?
Too much
Much
Fair
little
Too Little 